\title{
Journal of

\section{$\mathrm{Cu}, \mathrm{Zn}, \mathrm{Al}$ layered double hydroxides as precursors for copper catalysts in methanol steam reforming - $\mathbf{p H}$-controlled synthesis by microemulsion technique $\dagger$}

\author{
Stefanie Kühl, ${ }^{a}$ Matthias Friedrich, ${ }^{b}$ Marc Armbrüster $^{b}$ and Malte Behrens ${ }^{* a}$ \\ Received 24th November 2011, Accepted 14th March 2012 \\ DOI: 10.1039/c2jm16138a
}

\begin{abstract}
By co-precipitation inside microemulsion droplets a $\mathrm{Cu}$-based catalyst precursor was prepared with a $\mathrm{Cu}: \mathrm{Zn}:$ Al ratio of $50: 17: 33$. A pH-controlled synthesis was applied by simultaneous dosing of metal solution and precipitation agent. This technique allows for continuous operation of the synthesis and enables easy and feasible up-scaling. For comparison conventional co-precipitation was applied with the same composition. Both techniques resulted in phase pure layered double hydroxide precursors and finally (after calcination and reduction) in small $\mathrm{Cu}$ nanoparticles $\left(8 \mathrm{~nm}\right.$ ) and $\mathrm{ZnAl}_{2} \mathrm{O}_{4}$. By applying the microemulsion technique smaller $\mathrm{Cu} / \mathrm{ZnAl}_{2} \mathrm{O}_{4}$ aggregates with less embedded $\mathrm{Cu}$ particles were obtained. The microemulsion product exhibited a higher BET and specific $\mathrm{Cu}$ surface area and also a higher absolute catalytic activity in methanol steam reforming. However, the $\mathrm{Cu}$ surface area-normalized, intrinsic activity was lower. This observation was related to differences in interactions of $\mathrm{Cu}$ metal and oxide phase.
\end{abstract}

\section{Introduction}

The well known $\mathrm{Cu} / \mathrm{ZnO} / \mathrm{Al}_{2} \mathrm{O}_{3}$ catalysts which are used for different industrial syntheses, like methanol synthesis, are obtained by co-precipitation, followed by calcination and reduction. Most active catalysts are prepared from zincian malachite precursors. ${ }^{1,2}$ If aluminium is present in significant amounts (industrially applied $\mathrm{Cu}: \mathrm{Zn}: \mathrm{Al}$ composition: $\approx 60: 30: 10$ ), the ternary hydrotalcite (layered double hydroxide - $\mathrm{LDH})\left(\mathrm{Cu}_{1-x} \mathrm{Zn}_{x}\right)_{1-y} \mathrm{Al}_{y}(\mathrm{OH})_{2}\left(\mathrm{CO}_{3}\right)_{y / 2} \cdot m \mathrm{H}_{2} \mathrm{O}^{3}$ is usually observed as a by-phase after co-precipitation.

In a previous study we have shown that it is possible to obtain $\mathrm{Cu}$-rich (42-49 mol\%) phase pure $\mathrm{Cu}, \mathrm{Zn}, \mathrm{Al}$ hydrotalcite by coprecipitation. ${ }^{4}$ During calcination two different kinds of material were formed from the single phase precursors - amorphous areas with a $\mathrm{Zn}$ : Al ratio of $1: 2$, characteristic for the spinel-like $\mathrm{ZnAl}_{2} \mathrm{O}_{4}$, and granular areas with well crystalline $\mathrm{CuO}$, which are either depleted in $\mathrm{Zn}$ or $\mathrm{Al}$ (depending on the precursor composition). In the case of a precursor composition approaching the $\mathrm{Zn}: \mathrm{Al}$ ratio of $1: 2$ little or no segregation was

${ }^{a}$ Fritz-Haber-Institut der Max-Planck-Gesellschaft, Department of Inorganic Chemistry, Faradayweg 4-6, 14195 Berlin, Germany. E-mail: behrens@fhi-berlin.mpg.de; Fax: +49 30 8413-4405; Tel: +49 30 84134408

${ }^{b}$ Max-Planck-Institut für Chemische Physik fester Stoffe, Nöthnitzer Str. 40, 01187 Dresden, Germany

$\dagger$ Electronic supplementary information (ESI) available: More details for the microemulsion technique and the applied system with DLS data, phase diagrams and $\mathrm{N}_{2}$ physisorption isotherms as well as the determination of interface ratio. See DOI: $10.1039 / \mathrm{c} 2 \mathrm{jm} 16138 \mathrm{a}$ observed during calcination, suggesting the formation of a $\mathrm{CuO} /$ $\mathrm{ZnAl}_{2} \mathrm{O}_{4}$-type material in which the spinel phase is $\mathrm{X}$-ray amorphous. Such $\mathrm{Cu}, \mathrm{Zn}, \mathrm{Al}$ hydrotalcites are promising catalyst precursor materials as they show a homogeneous distribution of the metallic and oxidic components and very small $\mathrm{Cu}$ particles result after reduction. The main characteristic of these catalysts was that the resulting $\mathrm{Cu}$ particles were to a large extent not accessible by the reaction gas, as the particles were strongly embedded into the oxidic matrix. A large $\mathrm{Cu}$ surface area is, however, a prerequisite for high catalytic performance of $\mathrm{Cu} / \mathrm{ZnO} / \mathrm{Al}_{2} \mathrm{O}_{3}$ catalysts. ${ }^{5}$ Furthermore, it is known that in addition to a large $\mathrm{Cu}$ surface area also intrinsic factors can affect the surface normalized activity of $\mathrm{Cu}^{5,6} \mathrm{We}$ have recently shown that the embedding of $\mathrm{Cu}$ nanoparticles in $\mathrm{ZnO} / \mathrm{Al}_{2} \mathrm{O}_{3}$ may beneficially affect the intrinsic activity of the exposed $\mathrm{Cu}$ surface $\operatorname{area}^{7}$ in methanol synthesis, i.e. the activity or concentration of the active sites on the $\mathrm{Cu}$ surface. This effect is probably related to the stabilization of a strained and/or defective form of $\mathrm{Cu}$. Lattice strain ${ }^{8}$ and planar defects ${ }^{9}$ have been identified in previous studies as indicators for high intrinsic activity of the exposed $\mathrm{Cu}$ surface area.

The principle of using microemulsions as "nano-reactors" was shown to be a promising approach for the synthesis of nanoparticles in general ${ }^{10-13}$ and of $\mathrm{Cu}$-based catalysts in particular. ${ }^{14}$ A microemulsion (ME) is defined as a dispersion of two nonmiscible liquids, e.g. water and oil (typically an organic solvent), and a stabilizing surfactant (more details are given in ESI $\dagger$ ). In contrast to classical emulsions, microemulsions are characterized by a small droplet size $(5-100 \mathrm{~nm})$ and, hence, belong to colloidal 
systems. These droplets can be used as confined "nano-reactors". This technique has been utilized to synthesize hydrotalcites ${ }^{15-17}$ and was already applied using $\mathrm{pH}$-adjusted microemulsions. ${ }^{16,18}$ Herein, we present the ME synthesis of $\mathrm{Cu}, \mathrm{Zn}, \mathrm{Al}-\mathrm{LDH}$ by $\mathrm{pH}$-controlled co-precipitation within the ME-droplets using simultaneous dosing of metal salt solution and precipitation agent. Due to the simultaneous addition of all reactants, such synthesis processes can be operated continuously, which allows for easy and feasible up-scaling.

Applying the microemulsion technique to the LDH precursor system is supposed to influence the particle growth during the precipitation process. Furthermore, the present study aims to find a compromise to make small $\mathrm{Cu}$ particles more accessible to the reactant gas, but still providing improved interaction with the oxide to maintain stability during reaction and a high intrinsic activity - tested in methanol steam reforming (MSR). The nominal composition was chosen to $\mathrm{Cu}: \mathrm{Zn}: \mathrm{Al}=50: 17: 33$ as a high content of the active phase is desirable and makes the material comparable to industrially used catalysts. Based on our previous study, the $\mathrm{Zn}: \mathrm{Al}$ ratio of $1: 2$ should result in materials of a homogeneous $\mathrm{Cu} / \mathrm{ZnAl}_{2} \mathrm{O}_{4}$ microstructure. ${ }^{4}$

\section{Experimental}

\subsection{Materials}

Inspired by literature reports ${ }^{11,19,20}$ the technical non-ionic surfactant Marlipal O13/40 was chosen to apply the microemulsion technique to the synthesis of $\mathrm{Cu}, \mathrm{Zn}, \mathrm{Al}-\mathrm{LDH}$. The surfactant was added to the reaction medium water/cyclohexane. Cyclohexane was supplied by Roth with a purity of $99.9 \%$. Deionized water was taken from a Millipore water treatment system (MilliQ). The used surfactant Marlipal O13/40 $\left(\mathrm{C}_{21} \mathrm{H}_{44} \mathrm{O}\right.$ ) $)$ is a non-ionic surfactant of the alkyl polyglycolether type with a mean ethoxylation degree of four and was supplied by Sasol (Marl, Germany) with a purity of $98 \%$. The metal nitrates and bases were supplied by different companies with purities around $99 \%\left(\mathrm{Cu}\left(\mathrm{NO}_{3}\right)_{2}\right.$ - Roth, $\mathrm{Zn}\left(\mathrm{NO}_{3}\right)_{2}$ - Fluka, $\mathrm{Al}\left(\mathrm{NO}_{3}\right)_{3}$ - Riedel-de-Häen, NaOH - Riedel-de-Häen and $\mathrm{Na}_{2} \mathrm{CO}_{3}-$ by Roth) and were used without further purification.

\subsection{Microemulsion synthesis}

The water-in-oil microemulsions were prepared by mixing cyclohexane and the surfactant Marlipal O13/40 in a glass flask and adding either water or the salt solution. For the metal salt solutions the microemulsion formed spontaneously by gentle shaking in their stable temperature range (for phase diagrams see ESI $\dagger$ ). The base solution needed approximately $12 \mathrm{~h}$ until stable microemulsions were formed. Just for practical reasons the microemulsion synthesis of the $\mathrm{Cu}, \mathrm{Zn}, \mathrm{Al}$-hydrotalcite was carried out with just one microemulsion: A microemulsion $\left(\gamma=0.25,8 \% \mathrm{H}_{2} \mathrm{O}\right)$ of the aqueous solution of $\mathrm{NaOH}(0.3 \mathrm{M})$ and $\mathrm{Na}_{2} \mathrm{CO}_{3}(0.045 \mathrm{M})$ in cyclohexane which was stabilized with the surfactant Marlipal O13/40. The reaction was carried out by adding $\mathrm{Cu}, \mathrm{Zn}, \mathrm{Al}$ nitrate solution and the basic microemulsion at a constant $\mathrm{pH}$ value $(\mathrm{pH}=8 \pm 0.7)$ at $30{ }^{\circ} \mathrm{C}-\mathrm{pH}$ and temperature were controlled by an automated lab reactor system (Labmax from Mettler Toledo). A water-in-oil microemulsion without any salts was used as starting template in the vessel. The aqueous $\mathrm{Cu}^{2+} / \mathrm{Zn}^{2+} / \mathrm{Al}^{3+}$ nitrate solution $(\mathrm{Cu}: \mathrm{Zn}: \mathrm{Al}=$ $50: 17: 33$, total metal concentration: $c(M)=0.43 \mathrm{M})$ was dosed constantly and the basic microemulsion was dosed to maintain the $\mathrm{pH}$. Like this, the hydrotalcite was formed inside the water droplets. This ME synthesis approach can easily be scaled up by implementing a product overflow and running the co-precipitation continuously. Combined with recycling of the organic solvent, a cheap and controlled ME synthesis is possible. The product of the described ME synthesis was isolated by centrifugation, washing with acetone and drying at $100{ }^{\circ} \mathrm{C}$ for around $15 \mathrm{~h}$. Upon calcination in air at $330^{\circ} \mathrm{C}$ for $3 \mathrm{~h}$ the blue-green hydrotalcite was converted into the dark green mixed oxide. A reference catalyst was prepared similar as described by Behrens et al. ${ }^{4}$ by conventional co-precipitation under analogous conditions - i.e. using the same temperature, concentrations and drying as well as calcination procedure afterwards. The precursor samples are labeled "X-LDH", "X" being the short form of the synthesis method - "ME" for the microemulsion sample, "co" for the conventionally co-precipitated sample. The calcined samples are labeled "X-330", where 330 refers to the calcination temperature in ${ }^{\circ} \mathrm{C}$, and the reduced samples are labeled "X-red".

\subsection{Methods}

To determine suitable values for $\gamma, \alpha$ and $T$, the phase diagrams of all prepared microemulsions were explored by visual observation of the phase boundaries upon gradual change of the temperature (see phase diagrams in ESI Fig. S1 $\dagger$ ). The dynamic light scattering (DLS) measurements for droplet and particle size distributions were carried out using a Malvern ZetaSizer NS. The average composition of the precipitates was determined by inductively coupled plasma mass spectrometry (ICP-MS). X-ray diffraction (XRD) patterns were recorded on a STOE Stadi-P diffractometer in transmission geometry using $\mathrm{Cu}-\mathrm{K} \alpha_{1}$ radiation, a primary $\mathrm{Ge}$ monochromator and a $3^{\circ}$ linear position sensitive detector. The BET surface areas of precursor and calcined samples were determined by measuring the nitrogen adsorption-desorption isotherms with a Quantachrome Autosorb automatic BET-sorptometer at $-196{ }^{\circ} \mathrm{C}$ with nitrogen as the analysis gas. Prior to the analysis, the samples were outgased for $2 \mathrm{~h}$ at $100^{\circ} \mathrm{C}$. IR spectra were collected on a FTIR Perkin Elmer 2000 using the $\mathrm{KBr}$ disc technique. Thermogravimetric analyses (TG/DSC) were performed on a Netzsch STA449 thermobalance $\left(2 \mathrm{~K} \mathrm{~min}{ }^{-1}\right.$, synthetic air). Evolution of the gas phase during reaction was monitored with a quadrupole mass spectrometer (Pfeiffer, QMS200 Omnistar). Calcined samples were reduced in $5 \mathrm{vol} \% \mathrm{H}_{2}$ in Ar at a heating rate of $6 \mathrm{~K} \mathrm{~min}^{-1}\left(80 \mathrm{~mL} \mathrm{~min}^{-1}\right.$, end temperature $350{ }^{\circ} \mathrm{C}$, holding time $30 \mathrm{~min}$ ) by a temperature programmed reduction (TPR) in a fixed bed reactor (TPDRO-1100, CE instruments). The $\mathrm{H}_{2}$ consumption was monitored with a thermal conductivity detector. The copper surface area $(\mathrm{Cu} \mathrm{SA})$ of the reduced catalysts was determined in the same machine using $\mathrm{N}_{2} \mathrm{O}$ reactive frontal chromatography $\left(\mathrm{N}_{2} \mathrm{O}-\mathrm{RFC}\right){ }^{21} \mathrm{~N}_{2} \mathrm{O}$ oxidizes the $\mathrm{Cu}$ metal surface and is decomposed into $\mathrm{O}^{2-}$ and $\mathrm{N}_{2}$. The experiments were carried out at $30{ }^{\circ} \mathrm{C}$ to avoid subsurface oxidation..$^{22} \mathrm{~A}$ stainless-steel micro-reactor was used, which had an inner diameter of $4 \mathrm{~mm}$ and was filled with $95 \mathrm{mg}$ of the sieve fraction $(100-200 \mu \mathrm{m})$. The measurement was started by switching from pure $\mathrm{He}$ to $1 \mathrm{vol} \% \mathrm{~N}_{2} \mathrm{O}$ in $\mathrm{He}$ (Westfalen) by means of a four 
way valve. The amount of evolved $\mathrm{N}_{2}$ upon decomposition of $\mathrm{N}_{2} \mathrm{O}$ at the $\mathrm{Cu}(0)$ surface was monitored with a mass spectrometer (Pfeiffer, QMS Omnistar). The $\mathrm{Cu}$ surface area is calculated assuming a molar stoichiometry of $\mathrm{Cu}(\mathrm{s}) / \mathrm{N}_{2}=2$ and a value of $1.46 \times 10^{-19}$ copper atoms per square meter. ${ }^{23} \mathrm{SEM}$ images were taken in a Hitachi S-4800 (FEG) system. A Philips CM200FEG microscope operated at $200 \mathrm{kV}$ and equipped with a field emission gun and the Gatan imaging filter was used for TEM. The coefficient of spherical aberration was $\mathrm{Cs}=1.35 \mathrm{~mm}$. The information limit was better than $0.18 \mathrm{~nm}$. High-resolution images with a pixel size of $0.016 \mathrm{~nm}$ were taken at the magnification of 1'083'000× with a CCD camera, and selected areas were processed to obtain the power spectra (square of the Fourier transform of the image), which were used for measuring interplanar distances $( \pm 0.5 \%)$ and angles $\left( \pm 0.5^{\circ}\right)$ for phase identification. The catalytic activity was tested in the methanol steam reforming reaction $\left(\mathrm{CH}_{3} \mathrm{OH}+\right.$ $\mathrm{H}_{2} \mathrm{O} \rightarrow \mathrm{CO}_{2}+3 \mathrm{H}_{2}$ ) within a plug-flow reactor system (PID Eng\&Tech, $\mathrm{CH}_{3} \mathrm{OH}: \mathrm{H}_{2} \mathrm{O}=1: 1$ ) using a GC (CP 4900, Varian, columns: molsieve, PPU) for product analysis. The educt gas mixture contained nitrogen as a carrier gas and helium as an internal standard to calibrate the gas volumes, because unconverted water and methanol were removed prior to the GC using a cooling-trap and a Nafion membrane. A sieve fraction of $100-200 \mu \mathrm{m}$ of the calcined samples was diluted with $200 \mathrm{mg}$ of inert graphite. Both samples were reduced in hydrogen $(12 \mathrm{~h}$ at $180{ }^{\circ} \mathrm{C}$ and $3 \mathrm{~h}$ at $260^{\circ} \mathrm{C}$ ) before starting the steam reforming reaction which was carried out at $260^{\circ} \mathrm{C}$. Conversion of methanol was calculated using the amount of formed carbon oxides. Selectivity of $\mathrm{CO}_{2}$ was defined as $\mathrm{CO}_{2} /\left(\mathrm{CO}_{2}+\mathrm{CO}\right)-\mathrm{CO}$ was most likely produced by reverse WGS reaction.

\section{Results}

\subsection{Characterization - LDH precursor and calcined sample}

The microemulsion product is characterized in comparison to the co-precipitated one. The average composition of both precursors was determined by ICP-MS and was found to be close to the nominal values (Table 1). Both microemulsion and the conventional co-precipitation result in crystalline materials showing XRD patterns (Fig. 1) which are typical for LDH compounds and match the pattern reported for a sample $\mathrm{Cu}_{3} \mathrm{Zn}_{3} \mathrm{Al}_{2}(\mathrm{OH})_{16} \mathrm{CO}_{3} \cdot 4 \mathrm{H}_{2} \mathrm{O}$ (ICSD 37-629). ${ }^{24}$ The basal reflections of ME-LDH are clearly broadened, probably due to thinner platelets than in co-LDH. Furthermore, the (001) reflections are slightly shifted to higher angles and accordingly lower d values result (see Table 1). Such differences could be a consequence of random interstratification, but as the basal series is rational for both materials such random interstratification is not very probable. Furthermore, the observed differences could also result from changes in the interlayer composition (see below). In

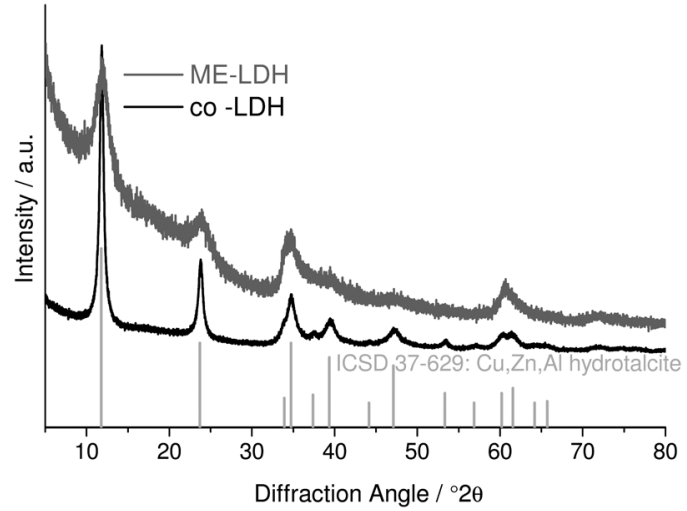

Fig. 1 XRD patterns of reference precursor (co-LDH) and of the product obtained by microemulsion synthesis (ME-LDH).

the SEM images (Fig. 2) it is visible that both products show the typical platelet-like morphology of hydrotalcites, with ME-LDH having a slightly smaller platelet diameter in comparison to coLDH (see Table 2). The obtained platelets are significant larger than the droplet diameter of the applied microemulsion (see ESI $\dagger$ ). This deviance is probably due to growth of the LDH platelets after the microemulsion is destroyed by centrifugation but the precipitate is still in its mother liquor. It has to be mentioned that the influence of applying the microemulsion synthesis on the platelet size is not as large as expected. However, the specific surface area is nearly doubled for ME-LDH (BET in Tab. 2, isotherms are presented in ESI $\dagger$ ) whereas the platelet diameter is just slightly decreased. Due to the large aspect ratios of the platelets, the specific surface area is mostly determined by basal surfaces, whereas the edges contribute little. Therefore, reducing the diameter of the platelets has only a minor effect on the specific surface area while reducing the thickness has a dramatic effect. This observation is in agreement with the broader XRD reflections of the basal planes. The thermal behaviour of the catalyst precursor samples was investigated by thermogravimetric measurements in synthetic air coupled with

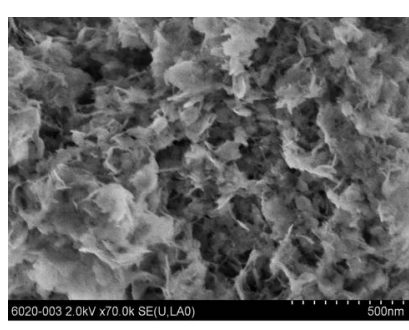

(a)

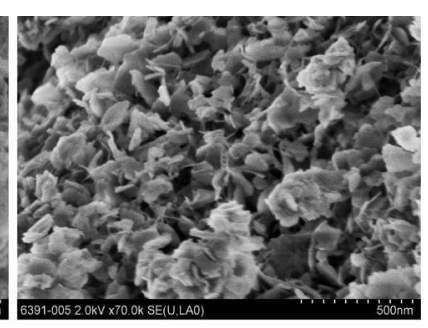

(b)
Fig. 2 SEM images of the precursors: (a) ME-LDH and (b) co-LDH.

Table 1 Metal composition of investigated samples (nominal concentration normalized to the total metal content, values measured by ICP are given in parentheses) and d-values of (001) reflections of XRD patterns

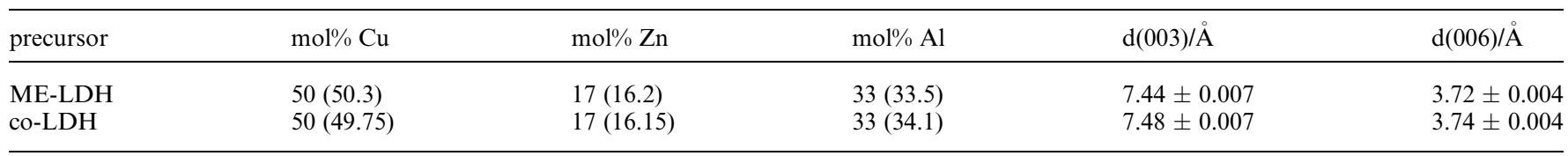


Table 2 Lateral particle size of the platelets determined from SEM (100 platelets), BET surface areas measured by $\mathrm{N}_{2}$ physisorption

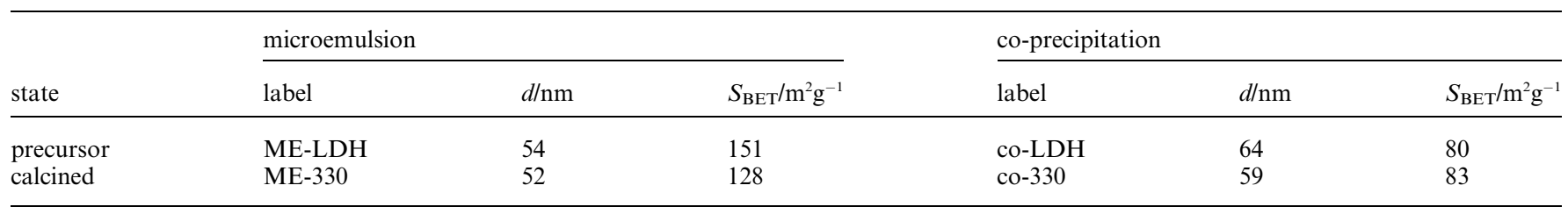

mass spectrometry (TG-MS). In general ME-LDH shows the same features of the thermal behaviour as typical for LDH compounds $^{25}$ like co-LDH (Fig. 3): (i) loss of surface water molecules around $70{ }^{\circ} \mathrm{C}$, (ii) evaporation of interlamellar water molecules between $100{ }^{\circ} \mathrm{C}$ and $140{ }^{\circ} \mathrm{C}$, (iii) dehydroxylation of the brucite-layer and loss of carbonate of the interlayer space between $140{ }^{\circ} \mathrm{C}$ and $220^{\circ} \mathrm{C}$. The last pronounced step of weight loss can be attributed to the well known, strongly bound (so called) high-temperature carbonate $\left(\mathrm{HT}-\mathrm{CO}_{3}^{2-}\right)^{4,26,27}$ at $515^{\circ} \mathrm{C}$ for ME-LDH and $620^{\circ} \mathrm{C}$ for co-LDH respectively. As already claimed elsewhere, ${ }^{28}$ a higher decomposition temperature of $\mathrm{HT}-\mathrm{CO}_{3}^{2-}$ is an indicator for strong interactions across interfaces

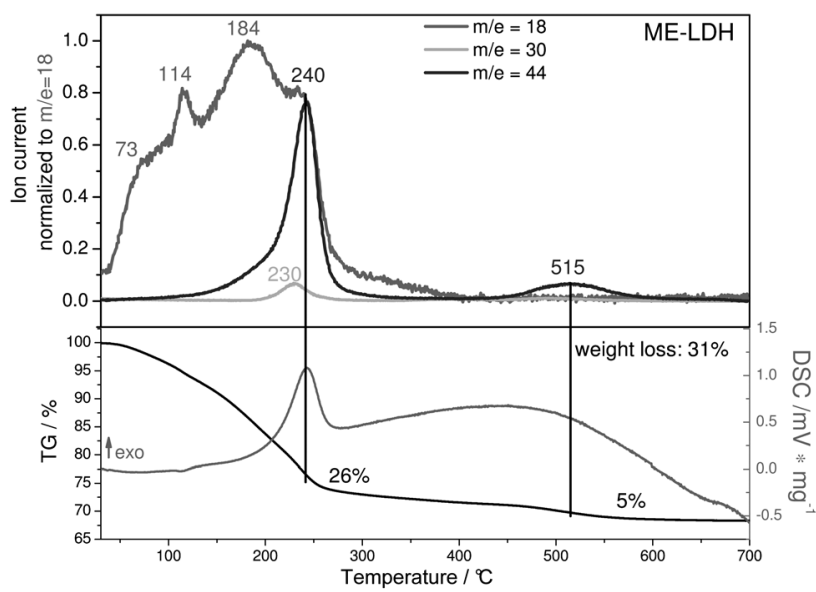

(a)

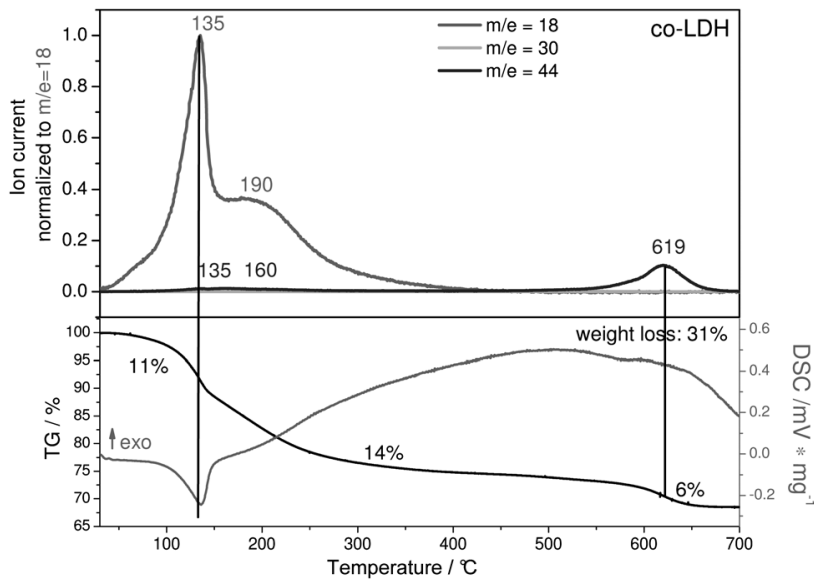

(b)

Fig. 3 Weight loss and MS spectra during calcination: (a) ME-LDH and (b) co-LDH; $\mathrm{m} / \mathrm{z}=18$ correlating with water evolution, $\mathrm{m} / \mathrm{z}=44$ with $\mathrm{CO}_{2}$ formation and $\mathrm{m} / \mathrm{z}=30$ is the NO trace-decomposition product of the nitrates. and grain boundaries which were formed during the first decomposition step. Accordingly, the lower thermal stability observed for ME-LDH results from a weaker interface contact of the oxidic $\mathrm{Cu}$ species with the $\mathrm{Zn}-\mathrm{Al}$ matrix. The total amount of nitrates is higher in ME-LDH compared to co-LDH, but carbonate was identified as the major anion by XRD (nitrate would give a larger inter-layer spacing ${ }^{25}$ ) and by comparison of the integrals of the corresponding MS traces (Fig. 3(a)). Additionally, the ME-LDH shows an exothermic event at $230{ }^{\circ} \mathrm{C}$ (Fig. 3(a)) which correlates with the formation of $\mathrm{CO}_{2}$ and $\mathrm{H}_{2} \mathrm{O}$ and can be assigned to the combustion of intercalated organic residues, e.g. acetone from washing - no indication of adsorbed acetone was found in the MS traces. For ME$\mathrm{LDH}$ the MS signal of the interlamellar water loss at $114{ }^{\circ} \mathrm{C}$ exhibits a significant lower intensity compared to the dehydroxylation step. As the weight loss is, furthermore, similar for both samples, organic molecules are assumed to substitute some water molecules in the interlayer of ME-LDH compared to the amount in co-LDH. By IR spectroscopy this is confirmed (see Fig. 4), as the water band of co-LDH at $1650 \mathrm{~cm}^{-1}$ is replaced by a vibrational band at $1550 \mathrm{~cm}^{-1}$ which is assigned to coordinated carbonyl - probably acetone (used for washing before drying) which remained within the interlayer during the drying process. This is also the most likely explanation for the difference in the interlayer spaces observed by XRD. Furthermore, the other peaks of the spectra $\left(570 \mathrm{~cm}^{-1}-\right.$ metal-OH deformation; $1360 \mathrm{~cm}^{-1}, 840 \mathrm{~cm}^{-1}$ - interlayer $\mathrm{CO}_{3}^{2-}$ deformation ${ }^{29}$ ), all belonging to the $\mathrm{LDH}$ compound, show a similar signature for both precursors. All spectra contain a nitrate band at $1385 \mathrm{~cm}^{-1}$ which results from co-intercalated nitrate anions in the $\mathrm{LDH}$ interlayers as well as impurities of the $\mathrm{KBr}$ used for dilution.

According to the TG-MS curve, all organic molecules are finally decomposed at $250{ }^{\circ} \mathrm{C}$. As we have shown before, a calcination temperature of $330{ }^{\circ} \mathrm{C}$ (for $3 \mathrm{~h}$ ) is suitable to

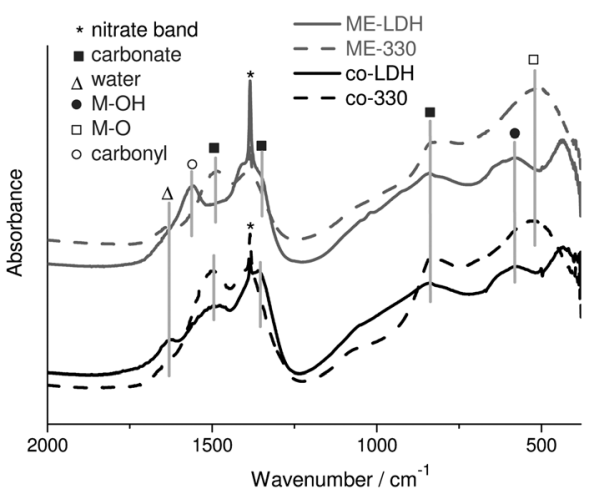

Fig. 4 IR spectra of precursor and calcined samples. 
dehydroxylate and decarboxylate the hydrotalcite ${ }^{4}$ and is also practicable for the one resulting from microemulsion. During calcination in air at $330^{\circ} \mathrm{C}$ both products were converted into nearly amorphous, carbonate containing mixed oxides (Fig. 5) as the oxide phases do not crystallize until the decarbonation step at a temperature above $500{ }^{\circ} \mathrm{C} .{ }^{4}$ These transformations were also observed by IR spectroscopy (see Fig. 4), where the M-OH band was replaced by the $\mathrm{M}-\mathrm{O}$ band $\left(510 \mathrm{~cm}^{-1}\right)$ and the carbonate band at $1360 \mathrm{~cm}^{-1}$ disappeared, whereas a shoulder at $1480 \mathrm{~cm}^{-1}$ remained or evolved in the case of the ME sample which is assigned to $\mathrm{HT}-\mathrm{CO}_{3}$. Furthermore, as the carbonyl band cannot be observed in the IR spectrum of ME-330, all remaining organic is, indeed, decomposed during calcination, as expected from TG-MS. ME-330 still shows the higher BET-SA (see Table 2), but a significant decrease was observed during the calcination process, whereas the platelet diameter (determined by SEM, Table 2) stays nearly constant for both samples. Hence, reduction of the specific surface area during calcination might be caused by an aggregation of the platelets which is supported by an increased inter-particle pore size between the platelets for ME-calc compared to ME-LDH (for details see ESI $\dagger$ ). Furthermore, SEM (Fig. 6) revealed that both samples maintained their morphology (Table 2) during calcination, showing again the similarity of the two materials. After calcination to $700{ }^{\circ} \mathrm{C}$ a crystalline product results for both samples which only contains $\mathrm{CuO}$ and $\mathrm{ZnAl}_{2} \mathrm{O}_{4}$ (see Fig. 7).

\subsection{Reduced catalyst}

The final $\mathrm{Cu} / \mathrm{ZnAl}_{2} \mathrm{O}_{4}$ catalysts, labeled as ME-red and co-red, resulted upon reduction of the $\mathrm{Cu}$ component of the calcined samples in hydrogen. The TPR profiles of both samples are depicted in Fig. 8. Both profiles have a similar shape, but the temperature of the maximum reduction rate is significant lower for ME-330, whereas the onset temperature is approximately the same. This observation is an indication for a particle size effect, as ME-330, which is resulting from the calcination of the LDH precursor, exhibits the smaller secondary particles (platy aggregates of $\mathrm{CuO}$ nanoparticles and oxide matrix, see platelet diameters in Table 2). The similar shape of the TPR profiles shows the similarity of the $\mathrm{Cu}$ phases present in both samples. By calibration using crystalline $\mathrm{CuO}$ it is possible to calculate the degree of reduction from the hydrogen consumption (ratio of formed $\mathrm{Cu}(0)$ to remaining oxidized $\mathrm{Cu}$ ). Where co-330 is nearly

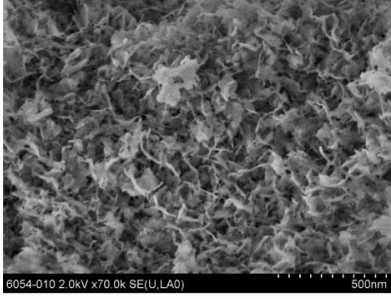

(a)

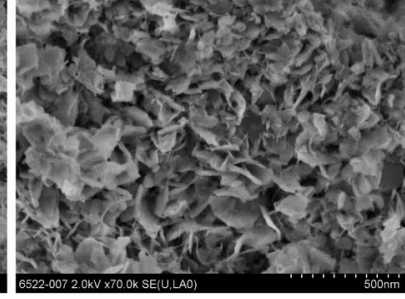

(b)
Fig. 6 SEM images of calcined samples: (a) ME-330 and (b) co-330.

completely reduced (98\%), a significant amount of $\mathrm{Cu}$ (II) is not reduced for ME-330 (90\% reduced). In agreement to our previous study, the TEM images show that the small $\mathrm{Cu}$ particles are embedded within the oxide matrix (see Fig. 9). Whereas the $\mathrm{Cu}$ particles have a similar size of below $8 \mathrm{~nm}$ for both samples (see Table 3 and Fig. 10), the secondary particles (aggregates of $\mathrm{Cu}$ nanoparticles and oxide matrix) appear less bulky for ME-red in accordance with the lower platelet thickness of the ME derived sample (see Fig. S6 in ESI $\dagger$ ). The Cu surface area of ME-red, is significantly higher (see Table 3 ) than the one of co-red. Due to the embedding of the $\mathrm{Cu}$ particles both catalysts have high interface ratios, i.e. the fraction of $\mathrm{Cu}$ particles which is not exposed to the gas atmosphere but present as interface to the oxide phase. This value (Table 3) can be calculated from the experimentally measured $\mathrm{Cu}$ surface area and the average $\mathrm{Cu}$ particle diameter determined by TEM assuming a spherical shape (formulas given in ESI $\dagger$ ). In ME-red a higher fraction of the $\mathrm{Cu}$ surface is exposed to gas (compare Table 3). Thus, by confining the growth of the LDH precursor particles, the microstructure of the resulting catalyst was modified leading to an increase of the exposed $\mathrm{Cu}$ surface area at the expense of interface area.

To compare their catalytic performance both catalysts were measured in methanol steam reforming. The results in Table 4 show a higher activity (hydrogen yield) of ME-red, whereas both catalyst show a similar stability (after $20 \mathrm{~h} \approx 69 \%$ of the conversion at $2 \mathrm{~h}$ ) of their performance. The higher activity is attributed to the improved microstructure implied by the application of the ME-technique during precursor preparation. However, the increase of activity of 7\% is low in relation to the difference in $\mathrm{Cu}$ surface areas of $66 \%$. This result indicates that the intrinsic activity is not constant for a given $\mathrm{Cu}$ particle size,

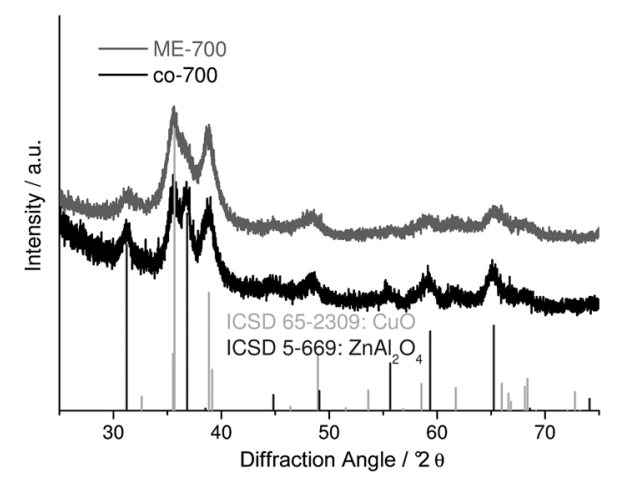

Fig. 5 XRD patterns of samples after calcination: ME-330 and co-330.

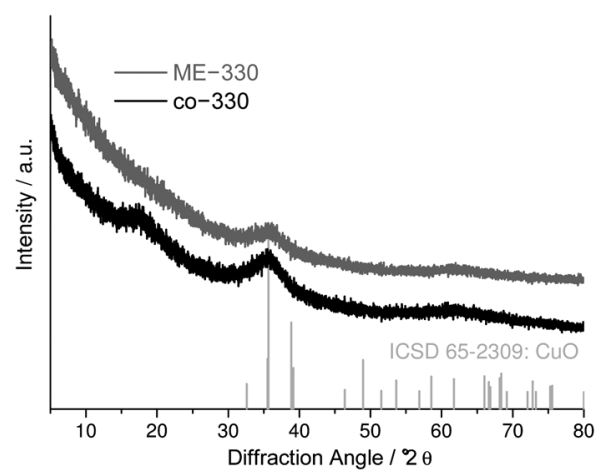

9636 | J. Mater. Chem., 2012, 22, 9632-9638 


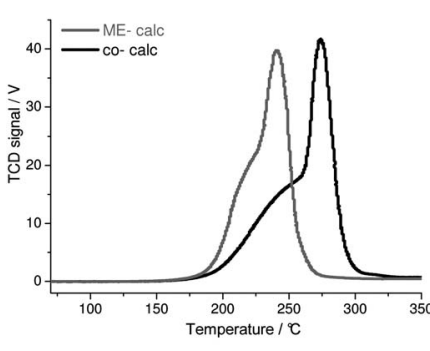

(a)

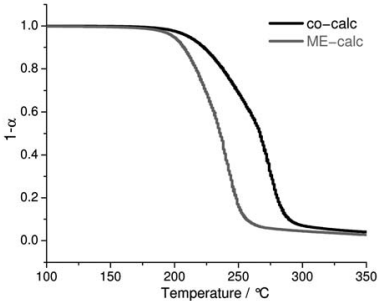

(b)
Fig. 8 TPR of investigated samples: (a) reduction profiles, (b) reduction progress.

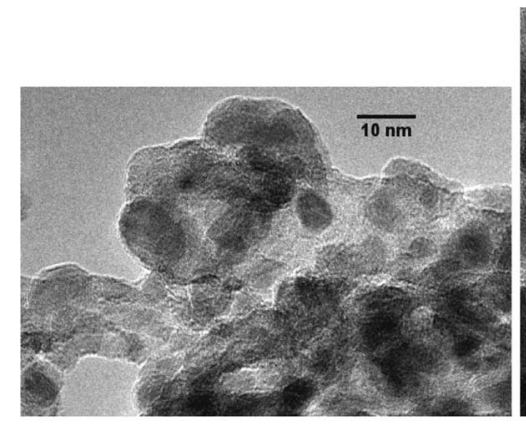

(a)

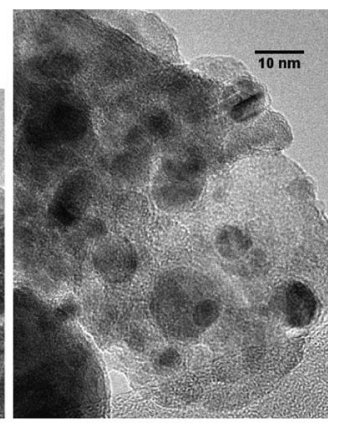

(b)
Fig. 9 TEM images of reduced samples: (a) ME-red and (b) co-red; $\mathrm{Cu}^{0}$ particles appear as dark spots, while the oxidic $\mathrm{Zn}$-Al-oxide matrix is brighter.

Table $3 \mathrm{Cu}$ particle size measured by TEM (>1000 particles), Cu surface area measured by $\mathrm{N}_{2} \mathrm{O}-\mathrm{RFC}$, interface ratio (IFR) and $\mathrm{Cu}$ surface area exposed to gas $(\mathrm{Cu} \mathrm{SA}$ exp $)$ calculated from TEM images

\begin{tabular}{lllll}
\hline & $d\left(\mathrm{Cu}^{0}\right) / \mathrm{nm}$ & $\mathrm{Cu} \mathrm{SA} / \mathrm{m}^{2} \mathrm{~g}^{-1}$ & $\mathrm{IFR} / \%$ & $\mathrm{Cu} \mathrm{SA} \exp / \%$ \\
\hline ME-red & 7.8 & $13.8 \pm 1.1$ & 69 & 31 \\
co-red & 7.7 & $8.3 \pm 1.1$ & 83 & 17 \\
\hline
\end{tabular}

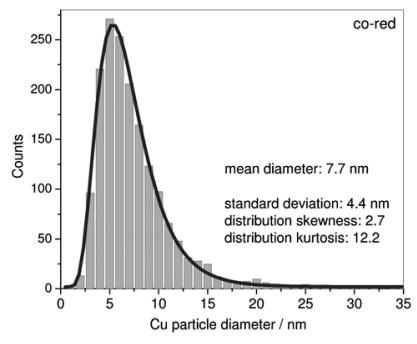

(a)

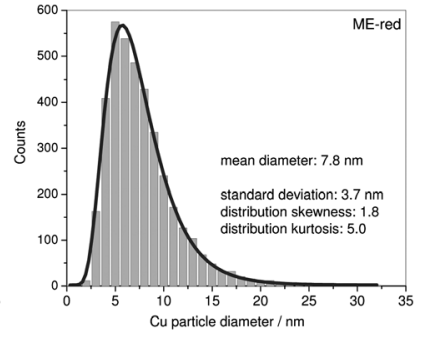

(b)
Fig. $10 \mathrm{Cu}$ particle size distribution after reduction determined from TEM images: (a) ME-red (3863 particles measured) and (b) co-red (1727 particles measured); the average $\mathrm{Cu}$ particle sizes are given in Table 3.

but depends heavily on the microstructure of the catalyst. In particular, ME-red exhibits a significantly lower interface ratio than co-red (see Table 3). This is in agreement with the weaker interface interaction which was concluded from the lower decomposition temperature of the high-temperature carbonate.
Table 4 Catalytic properties in methanol steam reforming

\begin{tabular}{lllll}
\hline & \multicolumn{2}{l}{$\mathrm{H}_{2}$ yield $/ \mathrm{mmol} \mathrm{g}^{-1} \mathrm{~h}^{-1}$} & & \\
\cline { 2 - 3 } & $2 \mathrm{~h}$ & $20 \mathrm{~h}$ & $X^{a} / \%$ & $S^{b} / \%$ \\
\hline ME-red & 336.1 & 232.4 & 58.8 & 99.0 \\
co-red & 314.8 & 215.7 & 63.1 & 99.5
\end{tabular}

${ }^{a}$ Conversion compared to feed methanol in $\%$ after $20 \mathrm{~h}$ on stream.

${ }^{b}$ Selectivity to $\mathrm{CO}_{2}$ in $\%$.

Thus, we assume that the interface interaction with the $\mathrm{ZnAl}_{2} \mathrm{O}_{4}$ matrix seems to beneficially affect the exposed $\mathrm{Cu}$ surface. A stabilization of a very active form of non-equilibrium copper has been proposed as the reason for an analogous effect in methanol synthesis. ${ }^{7}$ The present study suggests that a similar relation also exists for methanol steam reforming, which is formally the inverse methanol synthesis reaction.

\section{Conclusions}

We have demonstrated the possibility of applying a $\mathrm{pH}$ controlled co-precipitation for particle synthesis inside the water droplets of a water-in-oil microemulsion. Simultaneous addition of the reactants enables a continuous process and, thus, feasible up-scaling of this synthesis method. We have used this method to synthesize a $\mathrm{Cu}, \mathrm{Zn}, \mathrm{Al}$ hydrotalcite-based catalyst precursor materials. The BET surface area of the ME products (precursor and calcined one) is significantly higher due to thinner precursor platelets than the ones of the conventionally co-precipitated reference catalyst. Accordingly, the ME product exhibits less bulky secondary particles after calcination and reduction, i.e. aggregates of $\mathrm{CuO}$ or $\mathrm{Cu}$ nanoparticles and oxide matrix. The homogeneous distribution of all elements in the precursor state, which was observed for both systems, leads to small $\mathrm{Cu}$ particles below $8 \mathrm{~nm}$ for both samples. The catalyst resulting from ME exhibits indeed the higher $\mathrm{Cu}$ surface area, which is attributed to the smaller size of its $\mathrm{Cu} / \mathrm{ZnAl}_{2} \mathrm{O}_{4}$ aggregates and a lower embedding of the $\mathrm{Cu}$ particles. Consequently, the $\mathrm{ME}$ product exhibits the higher catalytic activity in methanol steam reforming compared to the co-precipitation product. However, the increase in $\mathrm{Cu}$ surface area does not scale with the increase in activity. The lower intrinsic activity of the catalyst resulting from microemulsion indicates that the $\mathrm{Cu}$ surface area is not the only influencing parameter to gain high activity, while effects of $\mathrm{Cu}$ particle size could be excluded. In case of the microemulsion product the lower intrinsic catalytic activity is attributed to a weaker interface contact of the $\mathrm{Cu}$ phase with the $\mathrm{Zn}-\mathrm{Al}$ matrix. Interface interactions between $\mathrm{Cu}$ and the oxide seem to beneficially affect the activity of the $\mathrm{Cu}$ particles and the optimal catalyst requires a compromise of exposed surface and interface.

\section{Acknowledgements}

The authors thank Edith Kitzelmann, Gisela Lorenz, Gisela Weinberg as well as Igor Kasatkin for their supporting measurements and Süd-Chemie AG is acknowledged for funding and collaboration. 


\section{References}

1 R. G. Herman, C. E. Bogdan, P. L. Kumler and D. M. Nuszkowski, Mater. Chem. Phys., 1993, 35, 233-239.

2 R. H. Höppner, E. B. M. Doesburg and J. J. F. Scholten, Appl. Catal., 1986, 25, 109-119.

3 F. Cavani, F. Trifiró and A. Vaccari, Catal. Today, 1991, 11, 173-301.

4 M. Behrens, I. Kasatkin, G. Weinberg and S. Kühl, Chem. Mater., 2010, 22, 386-397.

5 M. Kurtz, N. Bauer, C. Büscher, H. Wilmer, O. Hinrichsen, R. Becker, S. Rabe, K. Merz, M. Driess, R. A. Fischer and M. Muhler, Catal. Lett., 2004, 92, 49-52.

6 A. Mastalir, B. Frank, A. Szizybalski, H. Soerijanto, A. Deshpande, M. Niederberger, R. Schomücker, R. Schlögl and T. Ressler, J. Catal., 2005, 230, 464-475.

7 M. Behrens, A. Furche, I. Kasatkin, A. Trunschke, W. Busser, M. Muhler, B. Kniep, R. Fischer and R. Schlögl, ChemCatChem, 2010, 2, 816-818.

8 M. M. Günter, T. Ressler, B. Bems, C. Büscher, T. Genger, O. Hinrichsen, M. Muhler and R. Schlögl, Catal. Lett., 2001, 71, $37-44$.

9 I. Kasatkin, P. Kurr, B. Kniep, A. Trunschke and R. Schlögl, Angew. Chem., 2007, 119, 7465-7468.

10 B. L. Cushing, V. L. Kolesnichenko and C. J. O'Connor, Chem. Rev., 2004, 104, 3893-3946.

11 D. Adityawarmana, A. Voigt, P. Veit and K. Sundmacher, Chem Eng. Sci., 2005, 60, 3373-3381.

12 D. H. M. Buchold and C. Feldmann, Adv. Funct. Mater., 2008, 18, 1002-1011.

13 H. Goesmann and C. Feldmann, Angew. Chem., 2010, 122, 140214371.
14 J. Agrell, K. Hasselbo, K. Jansson, S. G. Jöras and M. Boutonnet, Appl. Catal., A, 2001, 211, 239-250.

15 F. Bellezza, A. Cipiciani, U. Costantino, M. Nocchetti and T. Posati, Eur. J. Inorg. Chem., 2009, 10, 2603-2611.

16 G. Hu and D. O'Hare, J. Am. Chem. Soc., 2005, 127, 17808-17813.

17 G. Hu, N. Wang, D. O'Hare and J. Davis, J. Mater. Chem., 2007, 17, 2257-2266.

18 L. Sun, Y. Zhang, J. Zhang, C. Yan, C. Lia and Y. Lu, Solid State Commun., 2002, 124, 35-38.

19 F. Rauscher, P. Veit and K. Sundmacher, Colloids Surf., A, 2005, 254, 183-191.

20 B. Niemann, F. Rauscher, D. Adityawarman, A. Voigt and K. Sundmacher, Chem. Eng. Process., 2006, 45, 917-935.

21 G. C. Chinchen, C. M. Hay, H. D. Vandervell and K. C. Waugh, J. Catal., 1987, 103, 79-86.

22 O. Hinrichsen, T. Genger and M. Muhler, Chem. Eng. Technol., 2000, 23, 956-959.

23 R. M. Dell, F. S. Stone and P. F. Tiley, Trans. Faraday Soc., 1953, 49, 195-201.

24 C. Busetto, G. del Piero, G. Manara, F. Trifiro and A. Vaccari, J. Catal., 1984, 85, 260-266.

25 A. de Roy, Mol. Cryst. Liq. Cryst. Sci. Technol., Sect. A, 1998, 311, 173-193.

26 B. Bems, M. Schur, A. Dassenoy, H. Junkes, D. Herein and R. Schlögl, Chem.-Eur. J., 2003, 9, 2039-2052.

27 G. J. Millar, I. H. Holm, P. J. R. Uwins and J. Drennan, J. Chem. Soc., Faraday Trans., 1998, 94, 593-600.

28 M. Behrens, F. Girgsdies, A. Trunschke and R. Schlögl, Eur. J. Inorg. Chem., 2009, 10, 1347-1357.

29 M. Turco, G. Bagnasco, U. Costantino, F. Marmottini, T. Montanari, G. Ramis and G. Busca, J. Catal., 2004, 228, 43-55. 